\title{
Propylene Glycol
}

National Cancer Institute

\section{Source}

National Cancer Institute. Propylene Glycol. NCI Thesaurus. Code C29388.

A propanediol that exists as a clear, colorless and hyg roscopic liquid and consists of propane where the hydrogens at positions 1 and 2 are substituted by hydroxyl groups. Propylene glycol is used as an organic solvent and diluent in pharmaceuticals and many other industrial applications. 